Identification with Media Characters Across the Lifespan

Courtney C. Baugh \& Rebekah A. Richert

University of California, Riverside 


\begin{abstract}
Identification is a construct rooted in psychoanalysis, where it was originally thought of as a defense mechanism (Freud, 1940/1949, p. 98). In more recent literature, identification (specifically, identifying with another person) is considered a process that requires both external (i.e., behavioral imitation) and internal (i.e., vicarious experience, imagination) mechanisms (Wollheim, 1974). Previous research has examined how humans come to know things about themselves over the lifespan, thus forming their own views about themselves; in other words, forming a self-identity. When examining the research on identity development, identifying with other people, and identifying with media characters, the development of own identity seems to parallel how humans relate to media characters at each stage of life. The purpose of this review is to: (1) examine identity as a construct; (2) examine identity development at each major stage of life; (3) bring attention to the problems media research tends to have when operationalizing the ways in which people can relate and react to media characters; and (4) examine how identifying and relating to media characters changes over the lifespan.
\end{abstract}

Keywords: identification, media, identity development 


\section{Identification with Media Characters Across the Lifespan}

Media characters or personas present a unique aspect to the way media can affect our everyday lives. Research has shown that how we view and relate to media characters can affect our views of ourselves (Konjin, Bijvank, \& Bushman, 2007) and the way we behave (Bell \& Dittmar, 2011; Gunther, Bolt, Borzekowski, Liebhart, \& Dillard, 2006; Shroff \& Thompson, 2006). It can also facilitate learning (Calvert, Strong, Jacobs, \& Conger, 2007; Gola, Richards, Lauricella, \& Calvert, 2012; Lauricella, Gola, \& Calvert, 2011), even in scenarios where learning from media has been found to be difficult (Cingel \& Krcmar, 2017; Troseth \& DeLoache, 1998).

Despite the importance of media characters to our everyday lives, research on how people relate to media characters has largely failed to distinguish between the ways we do so and to operationalize concepts like identification, affinity, similarity, parasocial relationships, and liking of media characters appropriately (Cohen, 2001). However, by looking at the developmental pattern of identification of the self and identification with media characters over the lifespan, it seems that the most salient identifying characteristics in each stage of life coincide with the characteristics people use to judge whether or not they relate to media characters. It can also be seen across the lifespan how people develop the necessary cognitive abilities to identify aspects of themselves and to be able to identify with other people, media characters included.

Two clarifications should take place. First, two main aspects of identity development will be examined: racial/ethnic identity and gender identity. The bulk of the research on how identity develops surrounds these two constructs, so it was possible to take a developmental perspective regarding ethnic and gender identity. Research exists on religious identity, for example, but it mainly focuses on adolescence (e.g., Hunsberger, Pratt, \& Pancer, 2001; Lopez, Huynh, \& Fuligni, 2011; Markstrom, 1999). The second clarification concerns the use of the 
terms identity and identification. For the purposes of this review, identity will refer to those aspects of a person that they use to define themselves, such as gender or ethnicity, and identification will refer to a process that allows one person to draw similarities between themselves and another.

This review will examine identification as a construct, how identification and identity develop over the lifespan, how people relate to media characters across development, and the similar patterns in the way identity/identification and relating to media characters develops across the lifespan. Gender, while not a construct that tends to change across the lifespan for a majority of people, tends to remain a salient characteristic for identifying with media characters across development.

\section{Theoretical Foundations of Identification}

\section{Identification and Imagination}

One of Freud's major contributions to the field of psychology was the emphasis he placed on subconscious processes. Freud viewed identification as one of those processes, more specifically, as a defense mechanism (Freud, 1940/1949, p. 98). To Freud, identification is a subconscious process in which a child desires to take the place of their same-gender parent, resulting in their identification with that parent. The child incorporates their parents' identity and values into themselves; parents, then, become part of the superego of the child. This subconscious process occurs as a result of the Oedipal complex, a compensation for the loss of their love-object (the opposite-gender parent), jealousy, or mortification (in the case of female children). 
Building off Freud's ideas, Wollheim (1974) believed that identification was an intricate process that must involve an internal component, distinguishing it from imitation, which is external and behavioral. Wollheim coins this internal component imagination. In other words, imagination is the internal mechanism of identification, while imitation is the external mechanism. To Wollheim, identification requires that we imagine ourselves to be this other target person, but also that we behave (or imagine that we behave) as this target person would; additionally, this person does not need to be the parent, as Freud suggested.

Bettelheim (1943), another identity theorist, suggested that identification does not need to include a purposeful undertaking of another identity other than oneself, but it could be thought of as sharing perspectives with another and viewing the world in a similar fashion. He argued that when children identify with the hero in a story, for example, they vicariously experience that character's triumph and learn that good has rewards (1976). (It is worth noting the resemblance this idea has to Bandura's (1997) social learning theory: when we see someone similar to ourselves succeed, then we believe we can also succeed. This theory will be discussed more later.) To reiterate the views of Freud (1940/1949), Wollheim (1974), and Bettelheim (1943; 1976), identification is a subconscious process by which a person leaves behind their own identity and adopts that of another person. This includes both thinking of oneself as the target character and behaving as the target character would, while viewing the world through a secondary point of view. The extent to which a person identifies with another is an informal measure of the degree to which that person is able to forget themselves in favor of another (Cohen, 2001).

\section{Identification: Part of Socialization}


Identification is an important part of early socialization, and our ability to identify with others develops early in life (Erikson, 1968). When children play with others, their games involve actions being taken by each game participant that each other participant must interpret and respond to in real time. This requires that children are able to anticipate the actions of their playmates, which allows them to practice perspective-taking (Mead, 1934). Perspective-taking facilitates children identifying with a community or group, or as Mead called it, the generalized other.

Erikson (1979) believed that the concept of identity is most crucial during adolescence, in the identity versus identity diffusion stage of psychosocial development. In his psychosocial theory of development, Erikson lays out several conflicts that must be resolved at different periods of life. The resolution of each conflict is thought to have lasting repercussions for the rest of the lifespan. In adolescence, children are working through the identity versus identity diffusion conflict. This conflict stems from a naturally developing desire to express oneself and achieve things that are meaningful to one's own culture. If an adolescent is in an environment that limits their ability to fully pursue their own desires, delinquent behavior occurs. To help them cope with the discomfort associated with being confused about their identity, adolescents form cliques or groups, giving them a sense of who they are based on which group they belong to. According to Erikson (1979), identity in adolescence becomes a combination of every role the child wished to fill or was forced to fill earlier in development to become like the caregivers, teachers, etc. in that child's life. Identity in adolescence is sought though peers and those who serve in leadership roles but are outside the family. To reiterate the points of Mead (1934) and Erikson (1979), identification allows children and adolescents to become productive members of their own society. Children and adolescents experiment with different personas in an attempt to 
locate one that fits them best. This aspect of identification, vicarious experience, can present as outward behavior or as imaginative, and is a critical part of how identification is conceptualized, especially in the context of media.

While adults have a firmer sense of self, children's identities are still developing and are more rudimentary the younger they are (Edmiston, 2008). According to Holland, Lachicotte, Skinner, and Cain (1998), children's identities form in two overlapping ways. First, identity is the result of children's participation in the practices of their own culture. Second, identity is produced as children are involved in social interactions. Their identities become more solidified over time, as they begin to recognize the social and ethical norms of the society in which they exist (Edmiston, 2008).

From the above-mentioned theorists, we have an idea of how identity and its importance unfold across the lifespan, with it becoming most critical during the adolescent years (Erikson, 1979). Now, identification and its mechanisms as they relate to media characters will be discussed, followed by a review of research examining how humans relate to other people and to media characters across the lifespan.

\section{Identification with Media Characters}

\section{Problems with Operationalization}

Since full identification involves an internal mechanism, it seems likely that repetitive internalization of other people's or media character's identities can have long-term effects, especially if these alternate identities are compelling and attractive (Cohen, 2001). It is not hard to imagine that characters seen in media can have a profound impact on the viewers of that media. Basil (1996) found that people who reported identifying with celebrities that were 
promoting health messages were more likely to adopt that same message. Even if this internalization is temporary, it can include some extreme behaviors (Meyrowitz, 1994). For example, Huesmann, Lagerspetz, and Eron (1984) found that if children identified with an aggressive character they saw on television, they were more likely to learn aggressive behaviors from that character (e.g., hitting other children).

Vicarious experience is the most researched function of identification by media researchers (Cohen, 2001). However, identification tends to be conflated with other similar constructs such as parasocial relationships. For this reason, measuring identification with media characters has been difficult. Audience members can respond to media characters in a variety of ways: liking/disliking characters (affinity; Newton, Buck, \& Woelfel, 1986), believing oneself to be similar to or different than characters (similarity; Reeves \& Miller, 1978), sexual or romantic attraction to characters (attachment; Cohen, 2001), imitation of things characters do (Hoffner, 1996), developing parasocial relationships with characters (Horton \& Wohl, 1956), or identifying with characters. Distinguishing between these dimensions of responses could ameliorate some of the ambiguity surrounding these constructs.

One approach that researchers have used to characterize identification involves defining identification in terms of liking a character, wanting to be like a character, and feeling similar to a character (Calvert et al., 2007; Liebes \& Katz, 1990; Maccoby \& Wilson, 1957). Some researchers have asked participants to rank the distance they felt between a character and themselves (Newton et al., 1986; Reeves \& Miller, 1978), resulting in a subjective measure of affinity and an uncertainty as to what was actually being measured (Cohen, 2001). Yet other researchers have conflated identification and imitation (Huesmann et al., 1984; Wiegman, Kuttschreuter, \& Baarda, 1992), which does not account for the internalizing dimension of 
identification (Cohen, 2001; Wollheim, 1974). Other studies have measured identification using a wider range of variables, including liking, similarity, friendship, role modeling, and perceived ability to work with the character in question (Basil, 1996); this approach views identification as variable intensities of different feelings that an audience member can have toward a character (Cohen, 2001).

Given these different approaches to measuring identification, four factors seem to be central in most operationalizations of identification: empathy, perspective-sharing, motivation/goal-sharing, and absorption (Cohen, 2001). Empathy refers to the extent to which an audience member feels she or he can share the feelings of the character. This entails not only feeling something on behalf of the character, but also feeling along with the character. Perspective-sharing can be measured by the extent to which one feels he or she can understand both the character and the character's behavior motivations. Motivation/goal-sharing refers to the extent to which a person internalizes and shares the goals of the character. Absorption refers to the extent to which self-awareness is lost when being exposed to that character (Cohen, 2001).

When a person identifies with a media character, they replace their role as audience member with the identity and role of the character in question (Cohen, 2001). This temporary role replacement strengthens with each exposure to the character and can be seen as an imaginative form of perspective-taking that can result in the audience member forgetting their own identity during exposure to that character. According to Oatley (1994), when we identify with a character from a book, we adopt that character's goals, process plot events in terms of how they affect that character, and vicariously experience emotions related to how those plot events interfere with the character's goals. (This again hearkens back to Bandura's (1997) social 
learning theory, in that when plot events happen that advance the target character's goals, the audience member should feel vicarious happiness or triumph (Oatley, 1994).).

In the context of media, identification is thought of as an audience member becoming unaware of themselves as an audience member, and imagines being the character they are watching or reading about (Cohen, 2001). This process can begin for a variety of reasons: something in the media product that causes the audience member to adopt the perspective of a character (Wilson, 1993), a particular liking for the character (Cohen, 1999), or recognizing that there are similarities between themselves and the character (Maccoby \& Wilson, 1957). Any of these can lead to a psychological attachment to the character (Oatley, 1999), causing the audience member to internalize that character's goals. This leads to empathy for the character and an adoption of that character's identity. The audience member feels and experiences the plot events vicariously along with the character, and identification with the character ends for a number of reasons: interruption of an external stimuli, an aspect of the media product, or the end of the story (Cohen, 2001). The results of this process in its entirety can include an increasing liking of the character or increased imitation of the character, but it can include negative emotions as well. If an audience member finds themselves strongly identifying with a "bad guy", this can lead to dissonance, fear, and guilt on the part of the audience member (Cohen, 2001).

To get a clearer picture of how identification fits into a media context, it may be helpful to discuss the other ways in which audience members can react to a media character. As mentioned earlier, the field of media research has had a hard time of distinguishing between, and then subsequently and accurately measuring, the following concepts.

\section{Identification and Parasocial Interaction/Relationships}


Horton and Wohl (1956) were the first to coin the term parasocial relationship to refer to a one-sided relationship between an audience member and a media persona/character. Audience members can feel emotionally close to a media character or persona does not reciprocate the feeling of emotional closeness or any of the social interactions the audience member engages in (referred to as parasocial interactions; Schramm \& Wirth, 2010). A parasocial relationship (PSR) differs from parasocial interactions (PSI) in that PSRs tend to last beyond the viewing experience and require more emotional investment than PSIs do (Schramm \& Wirth, 2010). Identification with a media character and having PSI/PSRs with that character can be differentiated from each other in terms of interactional mechanisms. When an audience member is engaged in a PSR, they imagine themselves interacting or being in a relationship with the character, but they do not lose their self-identity (Cohen, 1997). Conversely, when an audience member identifies with a media character, they lose their sense of self. The distinction between themselves and the character in question is gone, which is a required component of being able to interact with another person (Cohen, 2001). PSI can be thought of as a friendship, whereas identification requires being engrossed in the universe in which that character exists and in vicariously becoming that character (Auter, 1992). Additionally, identification is a psychoanalytic construct, while PSI/PSRs are interpersonal communication constructs (Horton \& Wohl, 1956).

\section{Identification and Liking, Similarity, or Affinity}

Liking a media character or persona, feeling similar to them, and experiencing a fondness toward them are all largely character judgments that audience members make regarding a media character. In order to do this, an audience member must make these judgments based on their own experiences, preferences, and ideas about what makes a person good or bad. In essence, 
being able to like another person, whether they are a media character or not, requires a sense of self-awareness. However, identification requires placing oneself inside the universe in which the character exists and imaging oneself to be that character, rather than continuing to exist outside of it and making judgments as a distanced audience member. Liking a character and feeling fondly toward them increase an audience member's sense of being a fan, while feeling similar to the character is likely based on judgments about the reality status of that character (Cohen, 2001).

\section{Identification and Imitation}

Imitation, as previously mentioned, is behavioral and is connected to the idea of observational learning, where audience members learn from a media character by watching their actions and monitoring the outcomes (Maccoby \& Wilson, 1957). Imitation can be thought of as the external mechanism of identification (Wollheim, 1974), but it is not the entire picture. Identification involves both an external mechanism (imitation) and an internal mechanism (imagining oneself to be the media character in question). Imitation is an important aspect of identification, but identification requires an internal component as well (Wollheim, 1974).

Many researchers interested in the concept of identification with media characters have not distinguished satisfactorily between identification, liking, similarity, affinity, imitation, and PSR/PSI. Often, researchers operationalize identification in one way, but conceptualize it in another so that what ends up being measured is actually liking, similarity, or a desire to imitate (Cohen, 2001). The following sections will explain how audience members relate to media characters across the lifespan. When possible, studies of true identification and its affects will be mentioned first, and the aforementioned additional ways in which audience members can relate to characters will be discussed second. 


\section{Identity Development and Identification Across the Lifespan}

\section{Infancy/Toddlerhood}

According to Hendrick (1951), writing from a psychoanalytic perspective, identification in infancy begins with imitation, or mostly voluntary and playful reproductions of another person's behavior. Hendrick cites several examples of 3-month-old infants crossing their fingers or 6-month-old infants playing peekaboo in response to a caregiver doing the same action. Indeed, research has shown that even newborn infants can imitate an adult opening their mouth and sticking out their tongue (Meltzoff \& Moore, 1983). More recent research has shown that the behavioral matching found in experiments on newborn imitation is not continuous with the mimicry that begins toward the end of the first year of life, and that early behavioral matching is temporarily masked by developmental events and reemerges later (Jones, 2007). While there has been mixed findings regarding neonatal imitation, some scholars believe that this imitative ability that neonates possess is not inherited or innate, but rather a skill that unfolds with the infant's increasing acquisition of different kinds of knowledge and skills during infancy and beyond (Oostenbroek, Slaughter, Nielsen, \& Suddendorf, 2013); in other words, we can think of neonatal imitation as a precursor to such things as social interaction and identification of the self as separate from others.

Another classic experiment showed that at 14 months of age, infants start to recognize that they are looking at themselves when they look into a mirror (Amsterdam, 1972). Additionally, by 18-19-months of age, infants begin to purposefully imitate another person and can realize the socially contingent nature of that person then imitating them in return (Asendorpf, Warkentin, \& Baudonniere, 1996). In fact, imitation in infancy has been thought to serve two functions: gaining understanding from observations that are confusing, and showing shared 
understanding with another person (Uzgiris, 1981). By the time children reach the age of 2, they can engage in emulation (understanding the goal of a modeled behavior but accomplishing that goal in a different way; McGuigan \& Whiten, 2009; Nielsen, 2006). From the aforementioned work, we can see that infants' ability to distinguish themselves as being separate from others emerges over the first year and a half of life, and their ability to employ, albeit rudimentarily, the external mechanism of identification is present almost at birth and becomes more intentional and sophisticated over the first two years of life.

From a theoretical standpoint, Lacan's (1949) mirror stage can also help to explain the precursors to children's ability to identify as or with another person. Drawing from research from the early 1900's, Lacan hypothesized that children as young as 6 months of age could identify their own image in a mirror, despite their cognitive and physical maturation being immature compared to older children and adults. This is called the mirror stage and can persist from 6-18 months of age. In this psychoanalytic perspective, the ego then becomes both an external object that the child identifies as separate from the self, and a goal that caregivers or others in the child's environment encourage the child to identify with ("Look at the baby in the mirror, that's you!'). The ability to see oneself as separate, or in other words, to be able to conceptualize something along the lines of, "I am myself, and that image over there is also myself" can be seen as a precursor to the ability to identify with others (Lacan, 1949). During the mirror stage of development, children are unable to care for themselves or move their bodies easily, and in that sense, their bodies are incomplete. However, the image they see of themselves in a mirror is whole, and this conflict persists throughout the lifespan: the image one holds of oneself does not completely match with their actual, physical self. While children will move on from the mirror stage being able to use pronouns to refer to themselves and continuing to form a 
self-image based on interactions with others, this conflict of holding an idea of oneself in one's mind and that image not matching up to reality can set the stage for wishful identification with other people (Johnston, 2018). To sum up, when children begin to recognize themselves in a mirror during infancy, they view themselves as separate and whole, and their true physical self does not match up to this. This lays the foundation for humans to hold an image of themselves in their mind and strive to make their actual selves match their ideal image (Johnston, 2018; Lacan, 1949). The ability to recognize oneself as both "me/I" and as "other" establishes humans' ability to identify with others.

An interesting line of research from Quinn, Yahr, Kuhn, Slater, and Pascalis (2002) has helped us understand the role gender plays in infants' preference for faces at 3-4 months of age. Finding that low-level perceptual factors could not explain why infants seemed to show a preference for female faces, Quinn et al. (2002) realized that the infants they studied all had females as their primary caregivers. Including infants with males as their primary caregivers showed that infants actually prefer faces that are gender-matched to that of their primary caregiver. This series of studies shows that infants, even before their first half year of life, can distinguish others from their primary caregiver, and can identify the gender of another adult. Being able to identify the gender of others is part of gender identity (Slaby \& Frey, 1975).

In terms of race/ethnicity, several studies have shown that infants prefer to look at faces of their own race versus other-race faces (Bar-Haim, Ziv, Lamy, \& Hodes, 2006; Kelly et al., 2007). While this is most likely due to environmental factors, such as being more accustomed to seeing faces of one's own ethnicity in infancy, these studies show that even at 3 months of age, infants can distinguish between the ethnicities of other people. 
Other lines of research have shown that infants/toddlers are capable of perspectivetaking, which is an important factor of identification with another person. One study showed that at 14 months old, toddlers will offer an adult food that the infant prefers, regardless of whether the adult has expressed disgust with the food. However, by 18 months, children offered the adult the food that the adult expressed a preference for, even if it was not the child's own preference (Repacholi \& Gopnik, 1997). Other research has shown that this ability to reason about the desires and intent of another person is contingent upon whether that person has displayed pro- or antisocial behavior; 16-month-olds will imitate the food choice of a person they have observed behaving prosocially, but will not imitate the food choice of a person that behaved antisocially, possibly because the child cannot trust the intentions of the latter (Hamlin \& Wynn, 2012). This research shows that children begin to perspective-take at a very young age and that their ability to do so is surprisingly nuanced.

In infancy and toddlerhood, children's ability to identify themselves as a person begins to emerge (Amsterdam, 1972; Asendorpf et al., 1996), as does their ability to imitate others (Hamlin \& Wynn, 2012; Meltzoff \& Moore, 1983). During this part of the lifespan, infants are also able to distinguish between the genders and ethnicities of other people (Bar-Haim et al., 2006; Kelly et al., 2007; Quinn et al., 2002) and have been shown to be able to take the perspective of another person in certain circumstances (Hamlin \& Wynn, 2012; Repacholi \& Gopnik, 1997). All of these factors are important in the development of the ability to identify with another person, and to identify aspects in oneself.

Identification with media characters. Research has shown that physical appearance is a salient characteristic to young children (Livesley \& Bromley, 1973), and this is true in regards to media characters as well (Jaglom \& Gardner, 1981). At 2 years of age, the first thing children 
will spontaneously remark upon is the physical appearance of a media character (Jaglom \& Gardner, 1981). The tendency to use physical appearance as a primary descriptor for media characters decreases with age, and children's ability to describe media characters becomes similar to how children describe real people (Wartella \& Alexander, 1977).

Even though much research has been done regarding the video deficit effect, or young children's inability to transfer learning from media to real life before the age of 2.5 years (Troseth \& DeLoache, 1998), some research has shown that promoting parasocial relationships and interactions in toddlers can facilitate learning where it may not have been otherwise possible (Gola et al., 2012). Toddlers were in one of three conditions: familiarized character condition (over a 3-month period, toddlers viewed videos of and played games featuring a media character that modeled a seriation task), unfamiliarized character condition (toddlers only saw the seriation demonstration video), or a control condition (toddler did not view seriation video or have any exposure to the character). Toddlers who had spent several months building a parasocial relationship with the character that modeled the seriation task performed significantly better on the task than toddlers who had only watched the seriation task or had watched nothing. This suggests that toddlers having a parasocial relationship with a media character can somewhat ameliorate the video deficit effect (Gola et al., 2012). Earlier research reported similar findings: when toddlers watch a character that they are already familiar with model a seriation task, their performance on the same task is better than toddlers who watched a character they had never seen before (Lauricella et al., 2011). Taken together, these results suggest that parasocial relationships or parasocial interactions can facilitate learning from media characters in toddlers. Additionally, toddlers' descriptions of media characters mirror the way they describe real people, 
first focusing on physical appearance and moving away from using this as a primary descriptor as they age (Sparks \& Cantor, 1986).

\section{Early Childhood}

In early childhood, imitation is the key to learning. Social learning, or acquiring information from other people, is crucial to everyday functioning (Bjorklund \& Causey, 2018, p. 402). Another way to think about social learning is that it encompasses situations or processes by which someone begins to behave like someone else (Boesch \& Tomasello, 1998). Bandura's social cognitive theory lays out five abilities that contribute to children's learning about their world and where they fit into it: symbolization (the use of symbols to reason about the world), forethought (ability to anticipate consequences of actions), self-regulation (adoption of standards of behavior based on social and moral norms), self-reflection (ability to analyze our own thoughts and behaviors), and vicarious learning (ability to learn by observing others; Bandura, 1989; Bandura \& Bussey, 1999).

Considering imitation, the external mechanism of identification, preschool-aged children, in contrast with 2-year-olds, will engage in imitation more frequently than they will engage in emulation (Gardiner, Greif, \& Bjorklund, 2011; Horner \& Whiten, 2005). Chimpanzees, on the other hand, engage in emulation, suggesting that children may be motivated to copy seemingly goal-irrelevant behaviors in order to maintain a social interaction (Horner \& Whiten, 2005). This aligns with ideas from Erikson (1979), Edmiston (2008), and Boesch and Tomasello (1998) in that being part of the social world naturally facilitates children's development of their own identity. 
In early childhood, children are beginning to develop the skills needed to identify with another person. One of these skills is perspective-taking. Some research has shown that 3-yearolds can engage in perspective-taking when they are planning to deceive someone; if they are not attempting to engage in deception, 3-year-olds perform egocentrically on false-belief tasks (Hala \& Chandler, 1996; Sullivan \& Winner, 1993). However, other research has found contradictory results, suggesting that children do not start using deception in a way that reflects perspectivetaking until they are 4 years old (Peskin, 1992; Sodian, 1991). This body of research shows that while children's perspective-taking ability is not completely developed in early childhood, by 3 years old, children do have a limited knowledge of the minds of other people.

In terms of gender identity, research has shown that by 2.5-3 years of age, children can correctly identify their own gender (Weinraub et al., 1984). Gender identity develops as children begin to realize that they belong to a gender group. This can result in increased motivation to be more like other members of their gender group, showing a preference for members of their own gender group, selective attention/memory in favor of information relevant to their own gender group, and interest in activities that are socially and culturally relevant to their own gender group (Martin \& Ruble, 2004). Gender stability, the knowledge that gender stays the same over time, is attained around the age of 4-5-years-old. Gender consistency, the knowledge that gender remains despite changes in outward appearance, develops at 6-7 years of age (Berenbaum, Martin, \& Ruble, 2007). Slaby and Frey (1975) found empirical evidence of this developmental sequence for gender constancy such that gender identity develops first, followed by gender stability, and then gender consistency; this sequence has been supported by other research (Eaton \& Von Bargen, 1981; Ruble et al., 2007). To sum up, children's ability to recognize their own gender and to attain a full gender identity develops over the early years of life. 
Research on racial/ethnic identity development has shown that children as young as 3-4 years of age are aware of their race/ethnicity and by age 4 are already expressing ethnicityrelated values (Goodman, 1952; Katz, 1982; Stevenson \& Stewart, 1958). Research in the area of racial/ethnic identity and awareness in children has focused on children's perceived and reported preferences for people or dolls of varying ethnicities (e.g., Clark \& Clark, 1947; Hunsberger, 1978). In a famous study, Clark and Clark (1947) presented 250 African American children ages 3-7 years with four dolls that only differed from each other on skin pigmentation (2 white, 2 brown). They presented these dolls to the children and asked them a series of questions requiring the children to choose between the dolls (e.g., "Give me the doll that looks bad", "Give me the doll that looks like you", "Give me the doll that looks like a White child"). The results suggest that by the age of 7 , a majority of children will correctly identify a doll that is of the same perceptual skin tone as they are. Additionally, a majority of these same children also reported that the White doll was their play preference, was the nice doll, and had a nice color. The doll technique used by Clark and Clark (1947) was used in 1978 by Hunsberger to research the same questions in regard to Native Canadian children. Hunsberger found similar patterns, such that both White and Native Canadian children preferred to play with a White doll, stated that the White doll was the nice one, and chose the Native Canadian doll as the one that "looks bad". Taken into historical context, this research suggests that children even as young as 3 can identify their own ethnicity and internalize any pervasive negative or positive messages about ethnicities, including their own. In other words, they are learning about their own ethnicity and how it fits into their culture.

During the preschool years, children start to recognize what they have in common with other people, especially peers. Children tend to choose playmates of the same gender as they are 
(Katz \& Kofkin, 1997). In fact, young children tend to call other children "friend" for a variety of reasons, including living in close proximity to each other, sharing a playspace/toy, being in the same class, or liking the same activities/having shared interests (Emiston, 2008). Research has shown that preschool children prefer masculine or feminine toys/colors if they are a boy or girl, respectively (Weisgram, Fulcher, \& Dinella, 2014). By 6 years old, children ascribe classically male activities to males and female activities to females, suggesting that gender is a salient human aspect to children in the 3-6-year-old age range (Boston \& Levy, 1991). In early childhood, children's primary identity is being a member of their family and/or of a care-group or preschool classroom (Edmiston, 2008). This implies that not only can children identify these aspects (gender, gender roles, group membership, and individual interests) in themselves and other people, but they are using this information to figure out where they themselves fit into the world.

Early childhood is also the time period that children begin engaging frequently in pretend play. During pretend play, children adopt alternate identities that they have either seen in media, real life, or have made up completely (Edmiston, 2008). Every alternate identity children adopt in pretend play is an opportunity for them to be positioned differently than they are in real life (e.g., a 4-year-old girl pretending to be Superman) and helps them practice the social cues and norms required to be a member of a group. This kind of play is known as symbolic play, which is play that involves substituting one thing for another (Pellegrini \& Bjorklund, 2004) and can take the form of sociodramatic play, in which children take on alternate identities and follow a storyline while inhabiting that identity (Bjorklund \& Causey, 2008, p. 184). This type of play is strongly influenced by both gender and culture. Boys tend to engage in sociodramatic narratives that involve power, aggression, and dominance, whereas girls' sociodramatic play tends to 
involve caretaking, relationships, and families (Pellegrini \& Bjorklund, 2004). In terms of cultural differences, children from more traditional cultures are more likely to involve tools and imitation of adult work in their play than children from more developed countries (Gosso, Otta, Morais, Ribeiro, \& Bussab, 2005).

To sum up, during their preschool years, children are developing the tools necessary for successful identification with another person: imitation and imagination. Children begin to imitate adult models to maintain social interactions (Horner \& Whiten, 2005) and are beginning to understand how the minds of other people work (Hala \& Chandler, 1996; Peskin, 1992; Sodian, 1991; Sullivan \& Winner, 1993). During this time period, children's gender identity is also developing (Eaton \& Von Bargen, 1981; Ruble et al., 2007; Slaby \& Frey, 1975). Additionally, by the time children turn 7, they understand their own ethnicity and how that ethnicity fits into the larger cultural dynamic (Clark \& Clark, 1947; Hunsberger, 1978). Children also become able to identify their own interests and those of others and can use this information to help them understand where they fit into their own world and how to become a member of a group (Boston \& Levy, 1991; Emiston, 2008; Katz \& Kofkin, 1997; Weisgram, Fulcher, \& Dinella, 2014). During the preschool years, children also start engaging in the types of pretend play that allow them to practice adopting alternate identities that are typically informed by the gender or culture group they belong to (Gosso et al., 2005; Pellegrini \& Bjorklund, 2004).

Identification with media characters. Preschool children tend to first evaluate media characters based on their physical appearance. Some research has shown that preschool-aged children are more likely to report feeling similar to a character of the same gender as they are than to a character of the opposite gender (Baugh, Richert, Schlesinger, \& Sakkis, 2019). Additionally, research has shown that preschool children's evaluations of the character the 
Incredible Hulk were more negative than older children, most likely because the younger children were evaluating based on physical appearance (Sparks \& Cantor, 1986). Additional research has found that preschool-aged children use physical appearance to predict whether a character will behave positively or negatively (Hoffner \& Cantor, 1985). When given information about a character's personality, children in early childhood will still make judgments based on their appearance, but this tendency decreases with age (Hoffner \& Cantor, 1985). Young children's ability to interpret inconsistencies in a character's behavior increases with age as well, but for young children, when a character behaves prosocially and then antisocially, young children are not likely to revise their impressions of that character (Collins, 1983). Lastly, during early childhood, children are less likely to recognize fear in televised characters than children during middle to late childhood (Wilson \& Cantor, 1985). In other words, through early childhood, children tend to make judgments about characters based on their physical appearance (Hoffner \& Cantor, 1985; Sparks \& Cantor, 1986). When characters behave inconsistently, young children are unlikely to change their opinions about that character (Collins, 1983), and children in early childhood are less likely to correctly identify emotions in media characters than older children (Wilson \& Cantor, 1985).

More contemporary research on how children in early childhood relate to media characters has shown that when children feel they are similar to a character, this can facilitate complex learning from that character. Calvert and colleagues (2007) found that when preschoolaged children reported feeling similar to Dora from Dora the Explorer, they displayed higher scores in divergent thinking, a form of learning in which the learner internalizes the goal of their teacher and reaches it through means that were not modeled. 
In early childhood, children begin relating to media characters in the same developmental pattern that they begin relating to real people, by focusing on physical appearance (Sparks \& Cantor, 1986). Children in this stage of the lifespan also have difficulty revising their views of media characters based on new information (Collins, 1983) and recognizing the emotions being displayed by media characters (Wilson \& Cantor, 1985). However, when children believe they are similar to a media character, they are more like to demonstrate learning from that character (Calvert et al., 2007).

\section{Middle/Late Childhood}

During middle and into late childhood, direct imitation of peers decreases as children age and the majority of imitated actions are verbal rather than behavioral (Abramovitch \& Grusec, 1978). Additionally, by the time children are in $3^{\text {rd }}-4^{\text {th }}$ grade, they are learning where they fit in with their peers and start to make judgments about their own social abilities in relation to those of their peers (Patterson, Kupersmidt, \& Griesler, 1990). Earlier studies (Coie \& Dodge, 1983, 1988; Hartup, Glazer, \& Charlesworth, 1967) developed a sociometric system for children to rate their classmates based on who is or is not their friend, classifying them into five groups: popular (receive many positive nominations from their peers), rejected (receive many negative nominations and few positive ones), neglected (receive few nominations, meaning they are neither generally liked nor disliked by their peers), average (receive an average number of positive and negative nominations), or controversial (receive many positive and negative nominations). Patterson et al. (1990) found that rejected children overestimated their own social (i.e., feeling/being easy to like, feeling/being popular among peers, having a lot of friends) and behavioral (i.e., being/feeling well-behaved, does the right thing, avoids trouble) competence in comparison to their peers' rating of their social/behavioral competence. Children of other 
statuses reported their own social/behavioral competence to be fairly accurate in relation to the ratings of their peers. This suggests that, barring familial problems (which seems to be a factor in children receiving a rejected status), children are able to accurately recognize their own place within their school classroom and can compare how others perform on similar measures in comparison to themselves.

Children's theory of mind, or the ability to reason about another person's thoughts, is still developing in middle and late childhood. Before aging out of early childhood, children are able to know that someone can hold a false belief and can use this knowledge to interpret that person's beliefs and actions (Wellman, Cross, \& Watson, 2001). By the time children have reached middle childhood, this ability is even more sophisticated. Research has shown that by 7 8 years of age, children can reason about second-order beliefs (Perner \& Wimmer, 1985). In other words, children know that people can have false beliefs about the world and beliefs, false or otherwise, about what is in another person's mind. However, children in middle and late childhood still have not reached adultlike theory of mind. The ability to interpret irony from a speaker is difficult for children at 9 years of age (Filippova \& Astington, 2008). Selman and Byrne (1974) found that children's ability to successfully take the perspective of a character in a story develops as they age, with children displaying more complex levels of perspective-taking around ages 8-10 years old. To reiterate, middle childhood is the developmental stage in which the abilities to reason about another person's thoughts and take the perspective of someone else become continue to develop and become more mature, but children in this stage are not yet adultlike in their theory of mind abilities.

In middle childhood, children become keenly aware of the gender roles within their society. This is the developmental stage in which children begin perceiving school subjects as 
masculine or feminine (Stein \& Smithells, 1969) and show interest and proficiency in these gender-typed subjects, respective to the child's own gender (Hilton \& Berglund, 1973). Peers also play a role in communicating to each other what types of interests and behaviors are normative for a child's gender (Lamb \& Roopnarine, 1979). Research has shown that in $3^{\text {rd }}$ and $6^{\text {th }}$ grade, children show a preference for activities, job aspirations, and household chores that align with gender-typical cultural roles (Etaugh \& Liss, 1992). In middle childhood, children show a preference for same-sex friends during play (Maccoby \& Jacklin, 1988). During elementary school, children boys have been found to engage in more physically aggressive play than girls, whereas girls tend to be involved in more constructive play (i.e., drawing) than boys. Additionally, during elementary school, boys are more accepted by other boys when they regularly display male-preferred play behavior (Moller, Hymel, \& Rubin, 1992). Some research has found that children in late childhood can recognize the extent to which they feel they are a typical member of their gender group, which is connected to feelings of internalized stress when children do not feel they fit in (Carver, Yunger, \& Perry, 2003). This body of research shows that as children move into elementary and prepare for the transition into adolescence, their knowledge of society's expectations for each gender becomes more solidified. Children show preferences for same-sex play partners and can recognize the extent to which they fit the gender norms of their own gender.

In terms of ethnic/racial identity, research has shown that children in middle/late childhood begin to form ingroup and outgroup preferences based on many things, including ethnicity (Katz \& Kofkin, 1997). In fact, children report viewing others of their own nationality more favorably than people of differing nationalities, regardless of whether they identify as being part of that nationality group (Bennett, Lyons, Sani, \& Barrett, 1998). Other research has shown 
that most children in middle childhood can correctly identify their own ethnicity (Bernal, Knight, Garza, Ocampo, \& Cota, 1990), and can use more sophisticated terms such as "DominicanAmerican" to describe themselves (Marks, Szalacha, Lamarre, Boyd, \& Coll, 2007). Though the research on ethnic/racial identity development in middle childhood is scarce (Marks et al., 2007), the research that does exist shows that children in middle childhood can verbally identify their own race/ethnicity and that knowledge of their own race/ethnicity affects how children view other people and view their own belonging to ethnic groups.

In summation, during middle and late childhood, children are still honing their ability to understand others and to take the perspective of others (Filippova \& Astington, 2008; Perner \& Wimmer, 1985; Selman \& Byrne, 1974; Wellman et al., 2001). They are also learning about where they fit in with their peers in terms of social and behavioral competency (Patterson et al., 1990). Their knowledge of cultural and social gender norms/expectations expands and affects their preferences, choices in play partners, and performance in school (Etaugh \& Liss, 1992; Hilton \& Berglund, 1973; Maccoby \& Jacklin, 1988; Stein \& Smithells, 1969). Children can also recognize the extent to which they fit into the prescribed gender roles and expectations in their society (Carver et al., 2003). During middle childhood, race/ethnicity plays a role in how children think about the groups they belong to (Bennett et al., 1998; Katz \& Kofkin, 1997), and children can identify their own ethnicity/race using sophisticated terms (Bernal et al., 1009; Marks et al., 2007). Even though direct imitation of peers decreases during middle and late childhood (Abramovitch \& Grusec, 1978), peers start to play a role in giving each other feedback about how they fit into the norms of society (Lamb \& Roopnarine, 1979) and into the social structure of their own classroom (Patterson et al., 1990). 
Identification with media characters. In middle and late childhood, children's focus on the physical appearance of media characters shifts to a focus on how that character behaves. Hoffner and Cantor (1985) found that when they manipulated a media character's behavior and physical appearance, 9-10-year-old children evaluated the character based on her behavior rather than her appearance, even if she had a scary appearance. Additionally, research has shown that during middle and late childhood, children are more likely than preschool-aged children to mention a character's motives when retelling the plot of a television show. Older children are also more likely to understand the relationships between a character's motives, behaviors, and the consequences that arise from them than younger children are (Wartella \& Alexander, 1977). Additionally, by the time children are in $5^{\text {th }}$ grade, they can predict a media character's emotional response to an event in the plotline by taking that character's past experience into account (Gnepp \& Gould, 1985). By the time children are 9 years old, they can start to infer complex emotions of media character's based on what the children perceive the character's expectations and interpretations of a situation to be (Flapan, 1968). To sum up, when children are in middle and late childhood, their focus in describing media characters shifts from being on physical appearance to behavior (Hoffner \& Cantor, 1985). They can make connections between complex emotional states, motives, behaviors, and consequences of behaviors when watching media (Wartella \& Alexander, 1977), and they can predict a character's emotional response based on the character's past experience (Gnepp \& Gould, 1985), expectations, and interpretations (Flapan, 1968). All of these are important components of being able to fully identify with a media character.

During middle to late childhood, children begin paying more attention to media characters and personas and start aspiring to be like them (Duck, 1989). In one study, children in 
$5^{\text {th }}-6^{\text {th }}$ grade were interviewed about a person they would most want to be like and a person they would least like to be like. Around $75 \%$ of children interviewed listed some type of media character as the person they would most want to be like, including professional athletes, pop stars, actors, and television characters. Conversely, around $66 \%$ of children listed a person known to the child as someone they would least like to be like, including classmates, family members, and friends (Duck, 1989). Another study found that 7-12-year-olds who were interviewed about their favorite television character selected same-gender characters as their favorite. Additionally, identification with male characters was predicted by intelligence and humor, while identification with female characters was predicted by attractiveness (Hoffner, 1996). This research suggests that during middle and late childhood, media figures have become children's primary role models (Duck, 1989), and that children are beginning to pay attention to traits outside of gender when reporting that they identify with a media character (Hoffner, 1996).

\section{Adolescence}

According to Erikson (1979), adolescence is a critical period of the development of identity. This is the stage in which occurs the identity versus identity diffusion conflict. The goal of this stage is to consolidate social roles. Adolescents begin to develop a sense of ego identity, which is the idea that the ability to continue being the same person over time ("inner sameness") matches the ideas we have about the inner sameness over time of others. In other words, whatever it is that keeps our core identity the same over time is what keeps others' identities the same over time as well. Adolescents are searching for their place in society, and their inability to settle on an occupational identity in this stage of life is the major disturbance of this conflict. In this stage, adolescents begin forming peer groups to help them cope with their own confusion about their identity (Erikson, 1979). For adolescents, peers become more 
important than they were in childhood. Research has shown that while parents' influence in matters of the future, such as continuing education or occupational choices, is still strong during adolescence, the influence of peers is more important for issues of the present, such as friendships, romantic relationships, hobbies, and free time (Brittain, 1968; Meeus, Oosterwegel, \& Vollebergh, 2002). While direct imitation of peers decreases during middle childhood (Abramovitch \& Grusec, 1978), adolescents do engage in peer imitation, seemingly for the purpose of fitting into their chosen peer group. Research has shown that direct peer imitation is an important factor in why adolescents start to smoke cigarettes and why they decide to quit smoking cigarettes (Chen, White, \& Pandina, 2001). To sum up, adolescents begin to include their peers when considering who they are and how they fit into society much more than they did in childhood.

The ability to take the perspective of another person continues to develop through adolescence and becomes increasingly sophisticated with age (Ritter, 1979). One study found that while younger and older adolescents had achieved level-1 perspective taking (the ability to mentally represent what another person can or cannot see; Flavell, Everett, Croft, \& Flavell, 1981), they frequently failed to use perspective/point-of-view information to solve a task requiring them to move objects to be in the view of another person (Dumontheil, Apperly, \& Blakemore, 2010). Additionally, Dumontheil and colleagues (2010) found that performance on this visual perspective-taking task improved from late adolescence to adulthood, suggesting that theory of mind interacts with executive function, which is not finished developing by late adolescence. To reiterate, the ability to take the perspective of another, an important part of identifying with others, continues to develop through adolescence. 
In terms of gender identity, little research has focused on the gender identity of typically developing adolescents, most likely because gender identity aligns with biological gender and stays fixed from early on in childhood for a majority of the population (Diamond \& Butterworth, 2008). However, some research has shown that during adolescence, children experience gender intensification, or an increased pressure to conform to culturally prescribed gender norms (Hill \& Lynch, 1983). Upon entering adolescence, boys report having a stronger gender identity than girls and report being more content with their gender. Boys also feel that they are under more pressure to conform to the gender norms of their society than girls do (Egan \& Perry, 2001). For most adolescents, their gender identity aligns with the gender normative behaviors they engage in (Steensma, Kreukels, de Vries, \& Cohen-Kettenis, 2013).

In thinking about how adolescents form an ethnicity/racial identity, it is useful to explain Phinney's (1993) three-stage model of ethnic identity in adolescence. Stage 1 is called unexamined ethnic identity. In this first stage, adolescents have not explored their ethnicity and ethnic identity. For those of a minority group, this can be categorized as an initial acceptance of majority culture's norms. Stage 2 is called ethnic identity search/moratorium. An identity crisis, or a turning point, occurs which causes the person to start searching for their own ethnic identity. In stage 3, ethnic identity achievement, adolescents have accepted and internalized their own ethnicity. Some research has found support for this model. Younger adolescents report positive views regarding being a member of their ethnic group (group-esteem), but this is likely because they are in stage 1 of Phinney's (1993) model. Conversely, middle adolescents report being in the ethnic exploration stage, and group-esteem is found to rise again in later adolescence (French, Seidman, Allen, \& Aber, 2006). Some factors that contribute to adolescents beginning to explore what being a member of their own ethnic group means are transitioning into high 
school (which tends to be more ethnically diverse than grade or middle school) and ethnicity (African and Latino Americans report the highest levels of change in group-esteem during adolescence, suggesting that they enter a period of stronger exploration; French et al., 2006).

In adolescence, the development of identity is crucial (Erikson, 1979). While parents remain important to adolescents, peers become even more so, and adolescents begin to define themselves as part of a peer group and behave in ways that maintain their membership in their chosen peer group (Brittain, 1968; Chen et al., 2001; Meeus et al., 2002). The ability to take the perspective of another person continues to develop through adolescence (Dumontheil, 2010; Ritter, 1979). During adolescence, gender intensification may occur, causing adolescents to feel more pressure to conform to their gender role (Hill \& Lynch, 1983), and most adolescents do conform to the gender-typical behaviors of their society (Steensma et al., 2013).

Identification with media characters. During adolescence, research has shown that children display wishful identification with media characters of the same gender as they are (Steinke, Applegate, Lapinski, Ryan, \& Long, 2012). Wishful identification is the extent to which a person wants to become like or imitate a media character (Feilitzen \& Linne, 1975). In one study, adolescents watched both animated and non-animated clips from popular television shows featuring scientist characters of both genders engaging in experiments or other scientific activities. Adolescents then answer questions such as, "I'd like to do the kinds of things he/she does on the show", and, "He/she is the sort of person I want to be like myself." Participants showed higher wishful identification scores for characters of the same gender as they were. This was especially true for boys, while girls only showed high wishful identification scores with female characters who were portrayed as dominant or who worked alone. Additionally, all participants showed higher wishful identification with non-animated characters (Steinke et al., 
2012). Other research on wishful identification has shown that adolescent boys who played a violent video game and reported wishing they were like a violent character in that video game displayed the highest levels of aggression, especially when the games they played were realistic and the players felt immersed in them (Konjin et al., 2007). To reiterate, adolescents identify with media characters of the same gender as themselves (Steinke et al., 2012), and imitate the behaviors of characters they wish they could be more like (Konjin et al., 2007).

Other research has also shown that media characters and personas can have a direct influence on adolescents' behavior. Shroff \& Thompson (2006) found that peer and media influences are more important than parental influences on adolescent girls' body image and eating habits. This relationship is especially strong for girls who report identifying with media models (Bell \& Dittmar, 2011). Additionally, media portrayal of cigarette-smoking habits increases the likelihood that adolescents will begin smoking, partly due to adolescents' perceived effect that the media has on their peers. In other words, adolescents see smoking in media and are more likely to take it up because they believe their peers will be more likely to adopt it as well (Gunther et al., 2006). Adolescents seem to rely on media for messages about how they should look and what they need to do in order to belong to their chosen peer group.

\section{Adulthood}

In adulthood, identity looks very different from other stages of development. According to Erikson (1979) and Marcia (2002), identity in adulthood moves through three main stages: intimacy, generativity, and integrity. In young adulthood, the goal is to be in a romantic, intimate relationship, and this is the primary place that young adults find their identity. In middle adulthood, those who have successfully handled the generativity versus stagnation conflict tend to be involved in many caregiving behaviors, believing that many people and 
causes are deserving of their care. In late adulthood, people are working through the integrity versus despair crisis. Those who have successfully managed this crisis generally appear to have profound wisdom to share based on their life experiences, have committed to a set of beliefs and values, and feel connected to others that are currently living and to their loved ones who have passed away (Marcia, 2002).

The ability to perspective-take continues to develop through adulthood. Dumontheil and colleagues (2010) found that while their adult age group made significantly fewer errors than the childhood and adolescence groups on a visual perspective-taking task, they still made errors approximately $45 \%$ of the time, indicating that the relationship between theory of mind and executive function is still developing (the adult group's mean age in this study was 22.8 years). However, little research has been conducted on theory of mind performance and development in adults. This is likely because theory of mind, after early to middle childhood, is affected by the maturation of other cognitive functions, such as executive function (Dumontheil et al., 2010). Other research backs up this claim. Researchers presented participants with the Imposing Memory Task, which is made up of five stories. Four of the stories (one story is a control story) require the participant to break down the larger problem into smaller, similar problems (recursive thinking) in order to understand the perspectives and intentions of the story's characters. A follow-up questionnaire was administered that examined the different levels of recursive thinking required to solve the problems presented in the stories and the extent to which participants engaged in these levels. The results showed that working memory was associated with all levels of recursive thinking, and linguistic comprehension was associated with third level recursive thinking (Valle, Massaro, Castelli, \& Marchetti, 2015). In other words, while we do not see much variability in performance on classical theory of mind tasks after middle childhood, 
theory of mind and its related abilities tend to be dependent on other cognitive processes (Dumontheil et al., 2010; Valle et al., 2015), which is possibly why research on adult theory of mind is lacking.

Since gender and ethnic identity are fairly stable after adolescence, not much research has been conducted on these topics. More salient to how adults identify themselves are concepts like occupation, family, relationship status/marriage, and ideological domains like religion or politics. Research has found that for middle-aged adults, work and family were the most salient parts of their own identity. Additionally, for adults who report foreclosure in 3 out of the 5 identity domains, about one third report that politics and religion were diffused (low commitment, low exploration; Fadjukoff, Pulkkinen \& Kokko, 2005). Fadjukoff et al. (2005) also found that most adults' identity development trajectory followed the expected pattern, from diffusion to achievement, in all domains except political identity. The predominance of this normative developmental identity trajectory could be another reason that research on identity in adulthood is scarce.

Identification with media characters. Once people reach adulthood, their wishful identification with media characters has become slightly more nuanced. In one study, participants between the ages of 18-28 years old completed questionnaires about their perceptions of and feelings about their favorite media characters. Unsurprisingly, participants reported higher levels of wishful identification with media characters of the same gender as themselves. However, both males and females differed in the attributes of the characters that predicted their wishful identification with characters of the same gender, while success and being admired predicted wishful identification with characters of the opposite gender. For samegender characters, women were more likely to identify with characters they perceived as 
successful, intelligent, attractive, and admired, while men were more likely to identify with characters they perceived as successful, intelligent, and violent (Hoffner \& Buchanan, 2005). Other research also suggests that high levels of aggression in adults is positively correlated with identifying with an aggressive media character, liking that character, and engaging in parasocial interactions with that character (Eyal \& Rubin, 2003). This suggests that while gender is still salient in terms of predicting identification with media characters, adults also pay attention to personality and lifestyle traits of the media characters they wish to be like.

Wishful identification can also affect the attitudes and behaviors of adults. In one study, young adults' viewing habits of a highly sexualized show was examined. Researchers found that if participants reported regularly watching the show, having strong parasocial relationships with the characters on the show, and identifying with the characters, participants were more likely to have permissive attitudes toward sex (a belief in sexual freedom; Bond \& Drogos, 2014). In another study, adults ages 18-42 were asked questions regarding their knowledge and level of identification with Magic Johnson, as well as their personal concerns about AIDS. The results showed that participants who reported identifying strongly with Magic Johnson were more likely to be personally concerned about the risk of contracting AIDS and were more likely to report intending to change their own high-risk sexual behaviors (Basil, 1996). This suggests that identifying with media characters can influence both the attitudes and behaviors of adults.

Video games also provide opportunities for adults to identify with media characters. Research has also shown that adults who play either shooting video games or racing video games report levels of identification with both the main character and the content of the game. This was found to alter the players' self-experience within the game (Klimmt, Hefner, Vorderer, Roth, \& Blake, 2010). Other research has suggested that when video game players identify with the 
characters in a video game, their enjoyment of the video game is increased, presumably because the full immersion identification process involves placing oneself in the character's shoes (Hefner, Klimmt, \& Vorderer, 2007). Additionally, identification with violent-sexist video game characters increased masculine beliefs for male participants only, which negatively predicted feelings of empathy for female victims of violence (Gabbiadini, Riva, Andrighetto, Volpato, \& Bushman, 2016). To sum up, identifying with video game characters can influence how players see themselves, how much they enjoy playing the game, and their aggressive attitudes.

\section{Conclusion}

When considering how personal identification develops across the lifespan, it seems that the way people relate to and identify with media characters follows a similar pattern. In each developmental stage, traits that are salient to humans in determining who they are and where they fit into society also seem to be the traits we use to judge whether or not we like a media character, want to be like them, or identify with them. For young children, gender becomes an important characteristic in identifying themselves (Weinraub et al., 1984), choosing who to play with (Emiston, 2008; Martin \& Ruble, 2004), and relating to media characters (Baugh et al., 2019; Hoffner \& Cantor, 1985; Sparks \& Cantor, 1986). During toddlerhood and early childhood, feeling similar to a media character can facilitate learning from that character (Calvert et al., 2007; Gola et al., 2012; Lauricella et al., 2011), despite the video deficit effect. In middle and late childhood, gender is still a salient identifying characteristic for children, as their knowledge of society's gender norms expands (Etaugh \& Liss, 1992; Hilton \& Berglund, 1973; Lamb \& Roopnarine, 1979; Stein \& Smithells, 1969). At the same time, their ability to reason about the thoughts and behaviors of others becomes more sophisticated (Perner \& Wimmer, 1985; Selman \& Byrne, 1974; Wellman et al., 2001). This is paralleled in the way children 
interact with and relate to media characters. When information about a character's intentions is available, children will use that information to judge a character rather than relying on physical appearance and can reason about complex relationships between emotions and actions (Flapan, 1968; Gnepp \& Gould, 1985; Hoffner \& Cantor, 1985; Wartella \& Alexander, 1977), but gender is still a salient characteristic for determining whether a child will identify with a media character (Duck, 1989; Hoffner, 1996).

Despite relatively few changes in gender identity for the majority of the population during adolescence, gender still remains a salient characteristic in terms of how adolescents view themselves within society (Egan \& Perry, 2001; Hill \& Lynch, 1983; Steensma et al., 2013). Peers become much more influential during adolescence (Brittain, 1968; Chen et al., 2001; Erikson, 1979; Meeus et al., 2001). The importance of gender and peers to adolescents is mirrored in how they view and relate to media characters during this stage of life. Adolescents report identifying most strongly with media characters of the same gender as they are (Steinke et al., 2012), and the perceived influence the media has on their peers influences adolescents to follow the media's advice in order to continue fitting into their chosen peer group (Gunther et al., 2006). During adulthood, characteristics such as work and family become the most salient identifying traits (Fadjukoff et al., 2005). Comparatively, while adults are still more likely to identify with media characters of the same gender as they are, other traits are equally important, such as perceived success, admiration, intelligence, attractiveness, and aggression (for men only; Hoffner \& Buchanan, 2005).

Media characters can influence the way we learn, the way we see ourselves, our attitudes about other people, and our outward behavior. However, future research should be careful to conceptually distinguish between identification with media characters and other similar 
constructs, such as liking, feeling similar to, and wanting to be like a media character.

Theoretically, these concepts are distinct but have been commonly treated as though they are the same (Cohen, 2001). Future research into how people relate to media characters should continue focusing on gender, as that seems to be a salient aspect in relating to media characters across the lifespan. 


\section{References}

Abramovitch, R., \& Grusec, J. E. (1978). Peer imitation in a natural setting. Child Development, 49(1), 60-65. doi: 10.2307/1128593

Amsterdam, B. (1972). Mirror self-image reactions before age two. Developmental Psychobiology, 5(4), 297-305. doi: 10.1002/dev.420050403

Asendorpf, J. B., Warkentin, V., \& Baudonniere, P-M. (1996). Self-awareness and otherawareness II: Mirror self-recognition, social contingency awareness, and synchronic imitation. Developmental Psychology, 32(2), 313-321. doi: 10.1037/0012-1649.32.2.313

Auter, P. J. (1992). TV that talks back: An experimental validation of a parasocial interaction scale. Journal of Broadcasting and Electronic Media, 36, 173-181.

Bandura, A. (1989). Human agency in social cognitive theory. American Psychologist, 44(9), 1175-1184. doi: 10.1037/0003-066X.44.9.1175

Bandura, A. (1997). Self-efficacy: The exercise of control. New York, NY: Freeman.

Bussey, K., \& Bandura, A. (1999). Social cognitive theory of gender development and differentiation. Psychological Review, 106(4), 676-713. doi: 10.1037/0033295X.106.4.676

Bar-Haim, Y., Ziv, T., Lamy, D., \& Hodes, R. M. (2006). Nature and nurture in own-race face processing. Psychological Science, 17(2), 159-163. doi: 10.1111/j.14679280.2006.01679.x

Basil, M. D. (1996). Identification as a mediator of celebrity effects. Journal of Broadcasting and Electronic Media, 40, 478-495. 
Baugh, C. C., Richert, R. A., Schlesinger, M. A., \& Sakkis, A. (March, 2019). Effects of gender and social realism on children's identification with media characters. Poster session presented at the Society for Research in Child Development, Baltimore, MD.

Bell, B. T., \& Dittmar, H. (2011). Does media type matter? The role of identification in adolescent girls' media consumption and the impact of different thin-ideal media on body image. Sex Roles, 65, 478-490. doi: 10.1007/s11199-011-9964-x

Bennett, M., Lyons, E., Sani, F., \& Barrett, M. (1998). Children's subjective identification with the group and in-group favoritism. Developmental Psychology, 34(5), 902-909.

Berenbaum, S., Martin, C. L., \& Ruble, D. N. (2007). Gender development. In W. Damon \& R. M. Lerner (Eds.), Child and adolescent development: An advanced course (647-681). Hoboken, New Jersey: John Wiley \& Sons, Inc.

Bernal, M. E., Knight, G. P., Garza, C. A., Ocampo, K. A., \& Cota, M. K. (1990). The development of ethnic identity in Mexican-American children. Hispanic Journal of Behavioral Sciences, 12(1), 3-24.

Bettelheim, B. (1943). Individual and mass behavior in extreme situations. The Journal of Abnormal and Social Psychology, 38(4), 417-452. doi: 10.1037/h0061208

Bettelheim, B. (1976). The uses of enchantment: The meaning and importance of fairy tales. New York: Knopf.

Bjorklund, D. F., \& Causey, K. B. (2018). Children's thinking (6 ${ }^{\text {th }}$ ed.). Thousand Oaks, CA: SAGE Publications, Inc. 
Boesch, C., \& Tomasello, M. (1998). Chimpanzee and human cultures. Current Anthropology, 39(5), 591-614. doi: 10.1086/204785

Bond, B. J., \& Drogos, K. L. (2014). Sex on the shore: Wishful identification and parasocial relationships as mediators in the relationship between Jersey Shore exposure and emerging adults' sexual attitudes and behaviors. Media Psychology, 17(1), 102-126. doi: $10.1080 / 15213269.2013 .872039$

Boston, M. B., \& Levy, G. D. (1991). Changes and differences in preschoolers' understanding of gender scripts. Cognitive Development, 6(4), 417-432. doi: 10.1016/08852014(91)90047-H

Brittain, C. V. (1968). An exploration of the bases of peer-compliance and parent-compliance in adolescence. Adolescence, 13, 445-458.

Calvert, S. L., Strong, B. L., Jacobs, E. L., \& Conger, E. E. (2007). Interaction and participation for young Hispanic and Caucasian girls' and boys' learning of media content. Media Psychology, 9(2), 431-445.

Carver, P. R., Yunger, J. L., \& Perry, D. G. (2003). Gender identity and adjustment in middle childhood. Sex Roles, 49(3/4), 95-109.

Chen, P-H., White, H. R., \& Pandina, R. J. (2001). Predictors of smoking cessation from adolescence into young adulthood. Addictive Behaviors, 26(4), 517-529. doi: 10.1016/S0306-4603(00)00142-8 
Cingel, D. P., \& Krcmar, M. (2017). Prosocial television, preschool children's moral judgments, and moral reasoning: The role of social moral intuitions and perspectivetaking. Communication Research, 46(3), 355-374. doi: 10.1177/0093650217733846

Cohen, J. (1997). Parasocial relations and romantic attraction: Gender and dating status differences. Journal of Broadcasting and Electronic Media, 41, 516-529.

Cohen, J. (1999). Favorite characters of teenage viewers of Israeli serials. Journal of Broadcasting and Electronic Media, 43, 327-345.

Cohen, J. (2001). Defining identification: A theoretical look at the identification of audiences with media characters. Mass Communication \& Society, 4(3), 245-264.

Coie, J. D., \& Dodge, K. A. (1983). Continuities and changes in children's social status: A fiveyear longitudinal study. Merrill-Palmer Quarterly, 29(3), 261-282.

Coie, J. D., \& Dodge, K. A. (1988). Multiple sources of data on social behavior and social status in the school: A cross-age comparison. Child Development, 59(3), 815-829. doi: $10.2307 / 1130578$

Diamond, L. M., \& Butterworth, M. (2008). Questioning gender and sexual identity: Dynamic links over time. Sex Roles, 59, 365-376.

Duck, J. M. (1989). Children's ideals: The role of real-life versus media figures. Australian Journal of Psychology, 42(1), 19-29.

Dumontheil, I., Apperly, I. A., \& Blakemore, S-J. (2010). Online usage of theory of mind continues to develop in late adolescence. Developmental Science, 13(2), 331-338. doi: 10.1111/j.1467-7687.2009.00888.x 
Edmiston, B. (2008). Forming ethical identities in early childhood play. New York: Routledge.

Egan, S.K., \& Perry, D.G. (2001). Gender identity: A multidimensional analysis with implications for psychosocial adjustment. Developmental Psychology, 37, 451-463.

Erikson, E. (1979). Identity and the life cycle. New York: W. W. Norton \& Company.

Etaugh, C., \& Liss, M. B. (1992). Home, school, and playroom: Training grounds of adult gender roles. Sex Roles, 26(3/4), 129-147.

Eyal, K., \& Rubin, A. M. (2003). Viewer aggression and homophily, identification, and parasocial relationships with television characters. Journal of Broadcasting and Electronic Media, 47(1), 77-98. doi: 10.1207/s15506878jobem4701_5

Fadjukoff, P., Pulkkinen, L., \& Kokko, K. (2005). Identity processes in adulthood: Diverging domains. Identity: An International Journal of Theory and Research, 5(1), 1-20. doi: 10.1207/s1532706xid0501_1

Feilitzen, C., \& Linne, O. (1975). Identifying with television characters. Journal of Communication, 25, 51-55.

Filippova, E. \& Astington, J. W. (2008). Further development in social reasoning revealed in discourse irony understanding. Child Development, 79(1), 126-138. doi: 10.1111/j.14678624.2007.01115.x

Flapan, D. (1968). Children's understanding of social interaction. Oxford, England: Columbia University, Teachers' College Press. 
Flavell, J. H., Everett, B. A., Croft, K., \& Flavell, E. R. (1981). Young children's knowledge about visual perception: Further evidence for the Level 1 - Level 2 distinction. Developmental Psychology, 17, 99-103.

French, S. E., Seidman, E., Allen, L., \& Aber, L. (2006). The development of ethnic identity during adolescence. Developmental Psychology, 42(1), 1-10. doi: 10.1037/00121649.42.1.1

Freud, S. (1949). An outline of psychoanalysis (J. Strachey, Trans.). New York: Norton \& Company, Inc. (Original work published in 1940).

Gabbiadini, A., Riva, P., Andrighetto, L., Volpato, C., \& Bushman, B. J. (2016). Acting like a tough guy: Violent-sexist video games, identification with game characters, masculine beliefs, and empathy for female violence victims. PLoS ONE, 11(4), e0152121. doi: 10.1371/journal.pone.0152121

Gardiner, A. K., Greif, M. L., \& Bjorklund, D. F. (2011). Guided by intention: Preschoolers’ imitation reflects inferences of causation. Journal of Cognition and Development, 12(3), 355-373. doi: 10.1080/15248372.2010.542216

Gnepp, J., \& Gould, M. E. (1985). The development of personalized inferences: Understanding other people's emotional reactions in light of their prior experiences. Child Development, 56(6), 1455-1464. doi: 10.2307/1130465

Gola, A. A. H., Richards, M. N., Lauricella, A. R., \& Calvert, S. L. (2013). Building meaningful parasocial relationships between toddlers and media characters to teach early mathematic skills. Media Psychology, 16(4), 390-411. doi:

$10.1080 / 15213269.2013 .783774$ 
Goodman, M. E. (1952). Race awareness in young children. Cambridge, MA: AddisonWesley. doi: 10.1037/14488-000

Gosso, Y., Otta, E., Morais, M., Ribeiro, F., \& Bussab, V. (2005). Play in hunter-gatherer society. In A. D. Pellegrini \& P. K. Smith (Eds.), The nature of play: Great apes and humans (pp. 213-253). New York: Guilford Press.

Gunther, A. C., Bolt, D., Borzekowski, D. L. G., Liebhart, J. L., \& Dillard, J. P. (2006). Presumed influence on peer norms: How mass media indirectly affect adolescent smoking. Journal of Communication, 56(1), 52-68. doi: 10.1111/j.14602466.2006.00002.x

Hala, S., \& Chandler, M. (1996). The role of strategic planning in accessing false-belief understanding. Child Development, 67(6), 2948-2966. doi: 10.1111/j.14678624.1996.tb01897.x

Hamlin, J. K., \& Wynn, K. (2012). Who knows what's good to eat? Infants fail to match the food preferences of antisocial others. Cognitive Development, 27(3), 227-239. doi: 10.1016/j.cogdev.2012.05.005

Hartup, W. W., Glazer, J. A., \& Charlesworth, R. (1967). Peer reinforcement and sociometric status. Child Development, 38(4), 1017-1024.

Hefner, D., Klimmt, C., \& Vorderer, P. (2007). Identification with the player character as determinant of video game enjoyment. In L. Ma, M. Rauterberg, R. Nakatsu (Eds.), Entertainment computing - ICEC 2007. doi: 10.1007/978-3-540-74873-1_6 
Henrick, I. (1951). Early development of the ego: Identification in infancy. The Psychoanalytic Quarterly, 20(1), 44-61. doi: 10.1080/21674086.1951.11925830

Hill, J. O., \& Lynch, M. E. (1983). The intensification of gender-related role expectations during early adolescence. In J. Brooks-Gunn \& A. Petersen (Eds.), Girls at puberty: Biological and psychosocial perspectives. Plenum: New York.

Hilton, T. L., \& Berglund, G. (1973). Sex differences in mathematics achievement - A longitudinal study. Journal of Educational Research, 67, 231-237.

Hoffner, C. (1996). Children's wishful identification and parasocial interaction with favorite television characters. Journal of Broadcasting and Electronic Media, 40, 389-402.

Hoffner, C., \& Buchanan, M. (2005). Young adults' wishful identification with television characters: The role of perceived similarity and character attributes. Media Psychology, 7(4), 325-351. doi: 10.1207/S1532785XMEP0704_2

Hoffner, C., \& Cantor, J. (1985). Developmental differences in responses to a television character's appearance and behavior. Developmental Psychology, 21(6), 1065-1074.

Holland, D., Lachicotte, W., Skinner, D., \& Cain, C. (1998). Identity and agency in cultural worlds. Cambridge, MA: Harvard University Press.

Horner, V., \& Whiten, A. (2005). Causal knowledge and imitation/emulation switching in chimpanzees (Pan troglodytes) and children (Homo sapiens). Animal Cognition, 8(3), 164-181. doi: 10.1007/s10071-004-0239-6

Horton, D., \& Wohl, R. R. (1956). Mass communication and para-social interaction. Psychiatry, 19, 215-229. 
Huesmann, L. R., Lagerspetz, K., \& Eron, L. D. (1984). Intervening variables in the TV violence-aggression relation: Evidence from two countries. Developmental Psychology, 20, 746-775. doi: 10.1037/0012-1649.20.5.746

Hunsberger, B. (1978). Racial awareness and preference of White and Indian Canadian children. Canadian Journal of Behavioral Science, 10(2), 176-180. doi: $10.1037 / \mathrm{h} 0081545$

Hunsberger, B., Pratt, M., \& Pancer, S. M. (2001). Adolescent identity formation: Religious exploration and commitment. Identity: An International Journal of Theory and Research, 1(4), 365-386. doi: 10.1207/S1532706XID0104_04

Jaglom, L. M., \& Gardner, H. (1981). The preschool television viewer as anthropologist. New Directions for Child and Adolescent Development, 1981(13), 9-30. doi: $10.1002 / \mathrm{cd} .23219811303$

Johnston, A. (2018). Jacques Lacan. In E. N. Zalta, U. Nodelman, \& C. Allen (Eds.), The Stanford encyclopedia of philosophy. Retrieved from https://plato.stanford.edu/entries/lacan/

Jones, S. S. (2007). Imitation in infancy: The development of mimicry. Psychological Science, 18(7), 593-599. doi: 10.1111\%2Fj.1467-9280.2007.01945.x

Katz, P. A. (1982). Development of children's racial awareness and intergroup attitudes. In L. G. Katz (Ed.), Current topics in early childhood education. New York: Ablex Publishing Corporation. 
Katz, P. A., \& Kofkin, J. A. (1997). Race, gender, and young children. In S. S. Luthar, J. A. Burack, D. Cicchetti, \& J. R. Weisz (Eds.), Developmental psychopathology: Perspectives on adjustment, risk, and disorder. Cambridge, UK: Cambridge University Press.

Kelly, D. J., Quinn, P. C., Slater, A. M., Lee, K., Ge, L., \& Pascalis, O. (2007). The other-race effect develops during infancy: Evidence of perceptual narrowing. Psychological Science, 18(12), 1084-1089. doi: 10.1111/j.1467-9280.2007.02029.x

Klimmt, C., Hefner, D., Vorderer, P., Roth, C., \& Blake, C. (2010). Identification with video game characters as automatic shift of self-perceptions. Media Psychology, 13(4), 323338. doi: 10.1080/15213269.2010.524911

Konjin, E. A., Bijvank, M. N., \& Bushman, B. J. (2007). I wish I were a warrior: The role of wishful identification in the effects of violent video games on aggression in adolescent boys. Developmental Psychology, 43(4), 1038-1044. doi: 10.1037/0012-1649.43.4.1038

Lacan, J. (1949). The mirror stage as formative of the function of the I. Ecrits: A Selection, trans. Alan Sheridan. New York: Norton, 1977.

Lamb, M. E., \& Roopnarine, J. L. (1979). Peer influences on sex-role development in preschoolers. Child Development, 50, 1219-1222.

Lauricella, A. R., Gola, A. A. H., \& Calvert, S. L. (2011). Toddlers' learning from socially meaningful video characters. Media Psychology, 14(2), 216-232. doi: $10.1080 / 15213269.2011 .573465$ 
Liebes, T., \& Katz, E. (1990). The export of meaning: Cross-cultural readings of "Dallas." New York: Oxford University Press.

Livesley, W. J., \& Bromley, D. B. (1973). Person perception in childhood and adolescence. Oxford, England: John Wiley \& Sons.

Lopez, A. B., Huynh, V. W., \& Fuligni, A. J. (2011). A longitudinal study of religious identity and participation during adolescence. Child Development, 82(4), 1297-1309. doi: 10.1111/j.1467-8624.2011.01609.x

Maccoby, E. E., \& Jacklin, C. N. (1974). The psychology of sex differences. Stanford: Stanford University Press.

Maccoby, E. E., \& Wilson, W. C. (1957). Identification and observational learning from films. Journal of Abnormal and Social Psychology, 55, 76-87.

Marcia, J. E. (2002). Identity and psychosocial development in adulthood. Identity: An International Journal of Theory and Research, 2(1), 7-28. doi: 10.1207/ S1532706XID0201_02

Marks, A. K., Szalacha, L. A., Lamarre, M., Boyd, M. J., \& Coll, C. G. (2007). Emerging ethnic identity and interethnic group social preferences in middle childhood: Findings from the Children of Immigrants Development in Context (CIDC) study. International Journal of Behavioral Development, 31(5), 501-513. doi: 10.1177/0165025407081462

Markstrom, C. A. (1999). Religious involvement and adolescent psychosocial development. Journal of Adolescence, 22(2), 205-221. doi: 10.1006/jado.1999.0211 
Martin, C. L., \& Ruble, D. (2004). Children's search for gender cues: Cognitive perspectives on gender development. Current Directions in Psychological Science, 13(2), 67-70. doi: 10.1111/j.0963-7214.2004.00276.x

McGuigan, N., \& Whiten, A. (2009). Emulation and "overemulation" in the social learning of causally opaque versus causally transparent tool use by 23 - and 30-month-olds. Journal of Experimental Child Psychology, 104(4), 367-381. doi: 10.1016/j.jecp.2009.07.001

Meeus, W., Oosterwegel, A., \& Vollebergh, W. (2002). Parental and peer attachment and identity development in adolescence. Journal of Adolescence, 25, 93-106.

Meltzoff, A. N., \& Moore, M. K. (1983). Newborn infants imitate adult facial gestures. Child Development, 54(3), 702-709.

Meyrowitz, J. (1994). The life and death of media friends: New genres of intimacy and mourning. In R. Cathcart \& S. Drucker (Eds.), American heroes in a media age (pp. 6281). Cresskill, NJ: Hampton.

Moller, L. C., Hymel, S., \& Rubin, K. H. (1992). Sex typing in play and popularity in middle childhood. Sex Roles, 26(7/8), 331-353.

Newton, B. J., Buck, E. B., \& Woelfel, J. A. (1986). Metric multidimensional scaling of viewers' perception of TV in five countries. Human Organization, 45, 162-170.

Nielsen, M. (2006). Copying actions and copying outcomes: Social learning through the second year. Developmental Psychology, 42, 555-565.

Oatley, K. (1994). A taxonomy of the emotions of literary response and a theory of identification in fictional narrative. Poetics, 23, 53-74. 
Oostenbroek, J., Slaughter, V., Nielsen, M., \& Suddendorf, T. (2013). Why the confusion around neonatal imitation? A review. Journal of Reproductive and Infant Psychology, 31(4), 328-341. doi: 10.1080/02646838.2013.832180

Patterson, C. J., Kupersmidt, J. B., \& Griesler, P. C. (1990). Children's perceptions of self and of relationships with others as a function of sociometric status. Child Development, 61(5), 1335-1349. doi: 10.2307/1130746

Pellegrini, A. D., \& Bjorklund, D. F. (2004). The ontogeny and phylogeny of children's object and fantasy play. Human Nature, 15(1), 23-43. doi: 10.1007/s12110-004-1002-z

Perner, J., \& Wimmer, H. (1985). “John thinks that Mary thinks that ...” Attribution of secondorder beliefs by 5- to 10-year-old children. Journal of Experimental Child Psychology, 39, 437-471,

Peskin, J. (1992). Ruse and representations: On children's ability to conceal information. Developmental Psychology, 28(1), 84-89. doi: 10.1037/0012-1649.28.1.84

Phinney, J. S. (1993). A three-stage model of ethnic identity development in adolescence. In M. E. Bernal \& G. P. Knight (Eds.), Ethnic identity: Formation and transmission among Hispanics and other minorities. SUNY Press: Albany, New York.

Quinn, P. C., Yahr, J., Kuhn, A., Slater, A. M., \& Pascalis, O. (2002). Representation of the gender of human faces by infants: A preference for female. Perception, 31, 1109-1121. doi: $10.1068 / \mathrm{p} 3331$

Reeves, B., \& Miller, M. M. (1978). A multidimensional measure of children's identification with television characters. Journal of Broadcasting, 22, 71-86. 
Repacholi, B., \& Gopnik, A. (1997). Early reasoning about desires: Evidence from 14- and 18month-olds. Developmental Psychology, 33(1), 12-21. doi: 10.1037/0012-1649.33.1.12

Ritter, E. M. (1979). Social perspective-taking ability, cognitive complexity and listeneradapted communication in early and late adolescence. Communications Monographs, 46(1), 40-51. doi: 10.1080/03637757909375989

Schramm, H., \& Wirth, W. (2010). Testing a universal tool for measuring parasocial interactions across different situations and media: Findings from three studies. Journal of Media Psychology, 22, 26-36. doi: 10.1027/1864-1105/a000004

Selman, R. L., \& Byrne, D. F. (1974). A structural-developmental analysis of levels of role taking in middle childhood. Child Development, 45(3), 803-806.

Shroff, H., \& Thompson, J. K. (2006). The tripartite influence model of body image and eating disturbance: A replication with adolescent girls. Body Image, 3(1), 17-23. doi: 10.1016/j.bodyim.2005.10.004

Sodian, B. (1991). The development of deception in young children. British Journal of Developmental Psychology, 9(1), 173-188. doi: 10.1111/j.2044-835X.1991.tb00869.x

Slaby, R. G., \& Frey, K. S. (1975). Development of gender constancy and selective attention to same-sex models. Child Development, 46(4), 849-856. doi: 10.2307/1128389

Sparks, G. G., \& Cantor, J. (1985). Developmental differences in fright responses to a television program depicting a character transformation. Journal of Broadcasting and Electronic Media, 30(3), 309-323. doi: 10.1080/08838158609386626 
Steensma, T. D., Kreukels, B. P. C., de Vries, A. L. C., \& Cohen-Kettenis, P. T. (2013). Gender identity development in adolescence. Hormones and Behavior, 64, 288-297.

Stein, A. H., \& Smithells, J. (1969). Age and sex differences in children's sex-role standards about achievement. Developmental Psychology, 1, 252-259.

Steinke, J., Applegate, B., Lapinski, M., Ryan, L., \& Long, M. (2012). Gender differences in adolescents' wishful identification with scientist characters on television. Science Communication, 34(2), 163-199. doi: 10.1177/1075547011410250

Stevenson, H. W., \& Stewart, E. C. (1958). A developmental study of racial awareness in young children. Child Development, 29(3), 399-409. doi: 10.2307/1126353

Sullivan, K., \& Winner, E. (1993). Three-year-olds' understanding of mental states: The influence of trickery. Journal of Experimental Child Psychology, 56(2), 135-148. doi: 10.1006/jecp.1993.1029

Troseth, G. L., \& DeLoache, J. S. (1998). The medium can obscure the message: Young children's understanding of video. Child Development, 69(4), 950-965. doi: 10.1111/j.1467-8624.1998.tb06153.x

Uzgiris, I. C. (1981). Two functions of imitation during infancy. International Journal of Behavioral Development, 4(1), 1-12. doi: 10.1177/016502548100400101

Valle, A., Massaro, D., Castelli, I., \& Marchetti, A. (2015). Theory of mind development in adolescence and early adulthood: The growing complexity of recursive thinking ability. Europe's Journal of Psychology, 11(1), 112-124. doi: 10.5964/ejop.v11i1.829 
Wartella, E., \& Alexander, A. (1977). Children's organization of impressions of television characters. Paper presented at the annual meeting of the International Communication Association, Chicago.

Weinraub, M., Clemens, L. P., Sockloff, A., Ethridge, T., Gracely, E., \& Myers, B. (1984). The development of sex role stereotypes in the third year: Relationships to gender labeling, gender identity, sex-types toy preference, and family characteristics. Child Development, 55(4), 1493-1503. doi: 10.2307/1130019

Weisgram, E. S., Fulcher, M., \& Dinella, L. M. (2014). Pink gives girls permission: Exploring the roles of explicit gender labels and gender-typed colors on preschool children's toy preferences. Journal of Applied Developmental Psychology, 35(5), 401-409. doi: 10.1016/j.appdev.2014.06.004

Wellman, H. M., Cross, D., \& Watson, J. (2001). Meta-analysis of theory of mind development: The truth about false-belief. Child Development, 72, 655-684.

Wiegman, O., Kuttschreuter, M., \& Baarda, B. (1992). A longitudinal study of the effects of television viewing on aggressive and prosocial behaviors. British Journal of Social Psychology, 31, 147-164.

Wilson, B. J., \& Cantor, J. (1985). Developmental differences in empathy with a television protagonist's fear. Journal of Experimental Child Psychology, 39(2), 284-299. doi: 10.1016/0022-0965(85)90042-6

Wilson, T. (1993). Watching television. Cambridge, England: Polity. 
Wollheim, R. (1974). Identification and imagination: The inner structure of a psychic mechanism. In R. Wollheim (Ed.), Freud: A collection of critical essays (pp. 172-195). New York: Anchor Press/Doubleday. 